\title{
Activating MYD88 Gene Mutation
}

National Cancer Institute

\section{Source}

National Cancer Institute. Activating MYD88 Gene Mutation. NCI Thesaurus. Code C157594.

A change in the nucleotide sequence of the MYD88 gene that that results in constitutive activation of both myeloid differentiation primary response protein MyD88 and its downstream signaling pathways. 